\title{
Recovery of inulin from Jerusalem artichoke (Helianthus tuberosus L.) in the small intestine of man
}

\author{
BY K. E. BACH KNUDSEN \\ Danish Institute of Animal Science, Department of Animal Physiology and Biochemistry, \\ Research Centre Foulum, PO Box 39, DK-8830 Tjele, Denmark \\ AND I. HESSOV \\ Department of Surgery I, Aarhus University Hospital, Amtssygehuset, Tage-Hansens Gade 2, \\ DK-8000 Aarhus C, Denmark
}

(Received 23 May 1994-Revised 20 October 1994 - Accepted 29 November 1994)

\begin{abstract}
The recovery of inulin, a naturally occurring $\beta(2 \rightarrow 1)$-fructan isolated from Jerusalem artichoke (Helianthus tuberosus L.), in the small intestine of man was studied in ileostomy subjects. The ileostomists were given a low-dietary-fibre diet based on white wheat bread and virtually free of inulin, and the same diet with the addition of $10 \mathrm{~g}$ and $30 \mathrm{~g}$ inulin product respectively, and the recovery and mean transit time (MTT) of inulin were estimated by tracking inulin in ileal effluent. The recovery of inulin was approximately $87 \%$ at both ingestion levels. MTT was 4.9 (SE 0.6) h at an intake of $10 \mathrm{~g}$ inulin product decreasing to 3.4 (SE $0-3$ ) $\mathrm{h}$ at an intake of $30 \mathrm{~g}$ inulin product. A significant change in the fructose: glucose ratio of inulin from ingestion (4-1) to recovery in ileal effluent (4-5-4.7) and a lower recovery of the glucose residue than of the fructose residue of inulin indicate that the low-molecularweight inulins are more sensitive to hydrolysis than the high-molecular-weight fragments. The loss of inulin during passage through the small intestine is presumably due to hydrolysis by either acids or enzymes and to microbial degradation by the microflora permanently colonizing the distal small intestine. The concentrations of lactic acid (LA) and short-chain fatty acids (SCFA) in frequently collected ileal effluents on the control day were approximately $6 \mathrm{mmol} / \mathrm{l}$ and approximately $55 \mathrm{mmol} / \mathrm{l}$ respectively. During periods with inulin ingestion the concentration of $L A$ increased to $18-26 \mathrm{mmol} / \mathrm{l}$ $(P<0.052)$, while the concentration of SCFA ran converse and decreased to 18-32 mmol/l $(P<0.023)$. The osmotic loads (68 and $204 \mathrm{mosmol} / \mathrm{l}$ ) associated with the ingestion of inulin product caused minor malabsorption of low-molecular-weight sugars.
\end{abstract}

Inulin: lleostomy: Recovery: Man

Naturally-occurring plant $\beta(2 \rightarrow 1)$-fructans are found as osmoregulators and storage carbohydrates in a variety of vegetables including onions, garlic, asparagus and artichokes, in fruits such as bananas, and in cereals (Hirst, 1957; De Bruyn \& Van Loo, 1991; Van Loo et al. 1995). Inulin is, for the purpose of this paper, defined as the polydisperse set of linear chain molecules made up of $D$-fructose residues linked to a terminal sucrose residue by means of $\beta\left(1-2^{\prime}\right)$ osidic bonds (De Leenheer \& Hoebregs, 1994). The degree of polymerization (DP) is within the range 2 to 60 (Van Loo et al. 1995). The low-molecularweight fractions of inulin (DP 2-20) are also known collectively as oligofructose (Van Loo et al. 1995).

Among the food plants, chicory (Cichorium intybus) and Jerusalem artichokes (Helianthus tuberosus L.) have proven to be rich sources of inulin and are well characterized as potential crops for commercial fructose production (Fleming \& GrootWassink, 1979). These fructans have a slightly sweet taste which, however, decreases 
with increasing DP. Inulin with a DP higher than 20 does not taste sweet any more (Archbold, 1940). This has led to the development of methods for isolation, purification and hydrolysis of higher-molecular-weight inulin from chicory by endoglycosidases.

The nutritional importance of inulin and other oligofructoses lies in their indigestibility. Only a small fraction is hydrolysed during their passage through the upper gastrointestinal tract (Yamashita et al. 1984; Stone-Dorshow \& Levitt, 1987; Rumessen et al. 1990). Such carbohydrates have several potential nutritional advantages as low-energy dietary supplements, as sources of carbohydrates for diabetics and more generally as dietary fibre (Roberfroid, 1993). Studies have shown that inulin has a smaller glycaemic effect than fructose (Yamashita et al. 1984; Rumessen et al. 1990), and it has beneficial effects on microbial metabolism in the large intestine. Studies with rats and in vitro studies with bacteria isolated from the large intestine of man have indeed shown that inulin is almost completely metabolized in the large intestine where it serves as a selective growth substrate for bifidobacteria (Hidaka et al. 1986; Wang \& Gibson, 1993). The nutritional energy value of inulin is consequently lower than that of sucrose, being in the range $4.2-6.3 \mathrm{~kJ} / \mathrm{g}$ (Roberfroid et al. 1993). Therefore inulin isolated from Jerusalem artichoke or hydrolysed inulin from chicory are naturally-occurring carbohydrates which may be used by the food industry, not only as sugar substitutes but also as replacements for fat (Deis, 1994).

Two human studies have concluded that inulin is completely unabsorbed in the small intestine of man (Stone-Dorshow \& Levitt, 1987; Rumessen et al. 1990). Both studies, however, were performed using the breath- $\mathrm{H}_{2}$ test which is considered to be inaccurate by some (Cummings \& Englyst, 1991). The ileostomy model provides a valuable alternative which may be used to study digestive physiology in man and it has often been used to study the small-intestinal excretion of nutrients (e.g. Langkilde et al. 1990; Schweizer et al. 1990; Cummings \& Englyst, 1991). In the present investigation we measured the recovery of inulin with a DP higher than 2 in the small intestine of man using the ileostomy model.

\section{EXPERIMENTAL}

\section{Subjects}

Seven subjects (six females and one male) with a median age of 38 (range 22-73) years participated in the study. All subjects had previously been proctocolectomized for ulcerative colitis (six) or familial polyposis coli (one). All were in good health and had wellestablished ileostomies without signs of small-bowel obstruction or ileostomy dysfunction. No resection of the small intestine or stomach had been performed and no antibiotics had been given within the last week. All had firm to thick ileostomic contents with a maximum of 1 litre/d. The study protocol was approved by the Aarhus County Medical Ethics Committee.

\section{Protocol}

The subjects were admitted to the hospital for $3 \mathrm{~d}$. On the first two successive days we studied the recovery of $10 \mathrm{~g}$ and $30 \mathrm{~g}$ respectively of the inulin product, while the control day followed a period of normal food intake. Since the inulin was recovered in ileal effluents in less than $11 \mathrm{~h}$, the authors do not believe that there was any carry-over effect that influenced the interpretation of the results.

\section{Diet}

The study was divided into three $24 \mathrm{~h}$ periods starting at 08.00 hours each day. The basal diet consisted of white wheat bread, butter, cheese, egg, ham, omelette, cured saddle of pork, pickled meat, fresh slices of meat, milk low in fat, water, tea, coffee and a glass of 
Table 1. Carbohydrate composition $(\mathrm{g} / \mathrm{kg}$ ) of the inulin product ingested

(Mean values with their standard errors for five determinations)

\begin{tabular}{lcl}
\hline \hline & Mean & SE \\
\hline Total carbohydrate & $919 \cdot 0$ & 0.04 \\
Glucose & 8.4 & 0.3 \\
Fructose & $18 \cdot 7$ & 0.3 \\
Sucrose & $184 \cdot 3$ & 1.0 \\
Inulin & 707.6 & 3.3 \\
Fructose: Glucose ratio of inulin & $4 \cdot 10$ & 0.046 \\
\hline
\end{tabular}

white wine with the dinner. The menus were the same on all three study days and provided: energy 8.8 MJ, protein $105 \mathrm{~g}$, fat $101 \mathrm{~g}$ and carbohydrate $159 \mathrm{~g}$. The day before the investigation the subject had her or his last meal at 20.00 hours, after which she or he was only allowed to consume water, tea and coffee. The main meals were served at $08.00,12.00$ and 18.00 hours.

The inulin product used in the present study was purified from Jerusalem artichoke (Danisco A/S, Danish Sugar Cooperation, Nakskov, Denmark) and had a carbohydrate composition as shown in Table 1 . The chain-length distribution (\%) was: DP3 12.9, DP4 12.9, DP5 11.2, DP6 9.8, DP7 8.2, DP8 6.2, DP9 4.5, DP10 2.8 and DP > 1031.5 .

The inulin product $(10 \mathrm{~g}$ or $30 \mathrm{~g})$ was dissolved in $200 \mathrm{ml}$ water and taken at 10.00 hours. The osmolarity of the load was $68 \mathrm{mosmol} / \mathrm{l}$ at the low intake level $(10 \mathrm{~g}$ inulin product) and $204 \mathrm{mosmol} / 1$ at the high intake level (30 g inulin product). The rationale of using this testing scheme was that the isolated inulin product typically will be incorporated into products consumed at intervals between main meals.

\section{Effluent}

Ileostomy effluent was collected by the subjects when they emptied or changed their bags every $2 \mathrm{~h}$ from 08.00 hours to 20.00 hours, again when they retired at 23.00 hours and the next morning at 08.00 hours. Each sample of effluent was frozen immediately after collection, stored at $-18^{\circ}$ and mixed thoroughly before samples were taken for analysis.

\section{Chemical analyses}

The dry matter (DM) content of ileal effluents was determined by freeze-drying and that of the inulin product by drying to constant weight at $70^{\circ}$ in a vacuum oven. All analyses of ileal effluent were made in duplicate while the carbohydrate composition of the inulin product was determined in five replicates. The low-molecular-weight (LMW) sugars (glucose, fructose and sucrose) and inulin (DP $>2$ ) were determined in individual collections of freeze-dried materials, while ash, $\mathrm{N}$, starch and non-starch polysaccharides (NSP) were determined in pooled freeze-dried samples. Organic acids were analysed either in pooled wet or freeze-dried materials.

Protein $(\mathrm{N} \times 6.25)$ was determined by the Kjeldahl method using a Kjell-Foss 16200 autoanalyser and ash was measured as described by the Association of Official Analytical Chemists (1990). Starch was analysed by a modification of the enzymic method of Bach Knudsen et al. (1987). Starch was gelatinized and quantitatively removed by incubation $\left(100^{\circ}, 60 \mathrm{~min} ; 60^{\circ}, 2 \mathrm{~h}\right)$ with a thermostable $\alpha$-amylase $\left(E C 3.2 .1 .1\right.$; Termamyl ${ }^{\star 8}$, Novo Nordisk A/S, Copenhagen, Denmark) and a $\beta$-glucanase-free amyloglucosidase (EC 3.2.1.3; Cat No. 1060 074, Boehringer Mannheim GmbH, Mannheim, Germany) 
and the resulting glucose monomers were quantified with a glucose oxidase reagent (EC 1.1.3.4; Cat No. 124001, Boehringer Mannheim GmbH). To correct for coloured substances in ileal effluent a blank was carried through the whole procedure. Total NSP and their constituent sugars in ileal effluent were determined as alditol acetates by GLC for neutral sugars using a modification of the Uppsala (Theander \& Aman, 1979; Theander \& Westerlund, 1986) and the Englyst (Englyst et al. 1982) procedures (Bach Knudsen et al. 1993), and by a colorimetric method for uronic acids (Scott, 1979).

LMW sugars and inulin in the inulin product and ileal materials were analysed as follows. Duplicate samples of approximately $400 \mathrm{mg}$ ileal effluent were weighed into $50 \mathrm{ml}$ centrifuge tubes with screw caps. Water $(25 \mathrm{ml})$ was added and the samples extracted for $70 \mathrm{~min}$ at $65^{\circ}$. During extraction the centrifuge tubes were mixed (vortex mixer) at least three times. The tubes were centrifuged $(2200 \mathrm{~g}, 20 \mathrm{~min})$ and a portion of the supernatant fraction was used directly for free glucose and fructose determinations, a portion was hydrolysed with $0.037 \mathrm{M}-\mathrm{H}_{2} \mathrm{SO}_{4}\left(80^{\circ}, 70 \mathrm{~min}\right)$ and a portion was used for HPLC determination. Glucose and fructose in the water extract before and after acid hydrolysis were quantified in a coupled enzymic reaction with $\mathrm{NADP}^{+}$. The reaction between glucose and $\mathrm{NADP}^{+}$is catalysed by the enzymes hexokinase $(E C 2.7 .1 .1$; Boehringer Mannheim $\mathrm{GmbH})$ and glucose-6-phosphate dehydrogenase (EC 1.1.1.49; Boehringer Mannheim $\mathrm{GmbH}$ ). Fructose-6-phosphate is first converted to glucose-6-phosphate by phosphoglucose isomerase (EC 5.3.1.9; Boehringer Mannheim $\mathrm{GmbH}$ ) and then quantified as above. The amount of NADPH formed during oxidation of $\mathrm{NADP}^{+}$was stoichiometrically related to the amount of glucose and fructose in the sample. The portion taken for HPLC determination was mixed $(9: 1)$ with internal standard (IS; arabinose, $11 \cdot 1 \mathrm{mg} / \mathrm{ml}$ ), to give a final IS concentration of $1 \mathrm{mg} / \mathrm{ml}$. A $2 \mathrm{ml}$ portion was filtered through a Bond Elute $\mathrm{C}_{18}$ cartridge (Analytichem International, Harbor City, CA, USA) prewetted with $2 \mathrm{ml}$ methanol and $5 \mathrm{ml}$ deionized water; the first $1.5 \mathrm{ml}$ eluate was collected and further filtered through a $0.22 \mu \mathrm{m}$ PTFE filter (Minisart NMLPF, Sartorius AG, Göttingen, Germany) and $20 \mu \mathrm{l}$ was used for HPLC determination. The HPLC system used consisted of a Modei 510 solvent delivery pump, Model 410 refractive index detector, temperature control module (Waters Chromatography Division, Milford, MA, USA), Model 7126 injector valve (Rheodyne Inc. Catati, CA, USA), Model LCI-100 recording integrator with builtin printer/plotter (Perkin-Elmer Inc., Norwalk, CT, USA) and a Shodex Ionpak KS-901 $(8 \mathrm{~mm} \times 300 \mathrm{~mm})$ resin-based column in the sodium form (Showa Denko K.K., Tokyo, Japan). Water was used as mobile phase, the flow rate was $0.6 \mathrm{ml} / \mathrm{min}$ and the column temperature was kept constant at $85^{\circ}$.

LMW sugars in the inulin product and ileal effluent were calculated as:

and inulin as:

$$
\text { LMW sugars }=\left(\text { Glc }_{F}+\text { Fru }_{F}+\text { Sucrose }_{\text {HPLC }}\right)
$$

$$
\text { inulin }=\left(\mathrm{Glc}_{\mathrm{A}}+\mathrm{Fru}_{\mathrm{A}}-\mathrm{Glc}_{\mathrm{F}}-\mathrm{Fru}_{\mathrm{F}}-\text { Sucrose }_{\mathrm{HPLC}}\right) \times 0.93
$$

where $\mathrm{Glc}_{\mathrm{A}}$ and $\mathrm{Fru}_{\mathrm{A}}$ are the total amounts of glucose and fructose estimated after acid hydrolysis, $\mathrm{Glc}_{\mathrm{F}}$ and $\mathrm{Fru}_{\mathrm{F}}$ are the amounts of the two monosaccharides found in the water

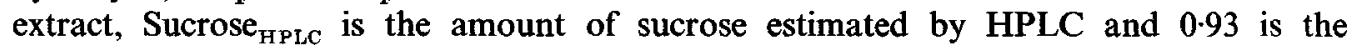
conversion factor from monosaccharides to oligosaccharides. The molecular weight distribution was determined by GLC according to the method of Quemener et al. (1994).

Total short-chain fatty acids (SCFA) were determined on wet or freeze-dried materials using a modification of the method of Fussell \& McCalley (1987). Duplicate samples of either $1.5 \mathrm{~g}$ wet ileal digesta or $0.5 \mathrm{~g}$ freeze-dried digesta were weighed into $50 \mathrm{ml}$ centrifuge tubes with screw caps. Oxalic acid $(0.3 \mathrm{M})$ was added to the samples; approximately $6 \mathrm{ml}$ (four times the wet weight) to wet samples and $10 \mathrm{ml}$ (twenty times the dry weight) to dry 
samples. The centrifuge tubes were capped, shaken mechanically for $1 \mathrm{~h}$ and then centrifuged ( $15000 \mathrm{~g}, 10 \mathrm{~min}$ ). A $5 \mathrm{ml}$ portion was mixed with $0.5 \mathrm{ml}$ pivalic acid (IS; $2.5 \mathrm{~g} / 1$ in $0.3 \mathrm{M}$-oxalic acid), centrifuged $(15000 \mathrm{~g}, 10 \mathrm{~min}$ ) and filtered through a $0.45 \mu \mathrm{m}$ PTFE filter. Separation of the individual SCFA was performed by GLC on a Perkin Elmer 8310 gas chromatograph (Perkin Elmer Inc. USA) equipped with flame-ionization detector. The column was a glass coil $(2 \mathrm{~m} \times 3 \mathrm{~mm}$ i.d.) packed with Carbopack B-DA 80-120 mesh (Supelco Inc., PA, USA). Column temperature was kept constant at $175^{\circ}$ and the injector and detector temperatures were maintained at $200^{\circ} . \mathrm{N}_{2}$ with a flow rate of $24 \mathrm{ml} / \mathrm{min}$ was used as carrier gas. Total lactic acid (LA) was determined in wet or freeze-dried samples by means of specific enzymes in a coupled enzymic reaction with $\mathrm{NAD}^{+}$. Duplicate samples of either $5 \mathrm{~g}$ wet ileal digesta or $0.5 \mathrm{~g}$ freeze-dried digesta were weighed into $50 \mathrm{ml}$ centrifuge tubes with screw caps. To the wet ileal samples was added $25 \mathrm{ml}$ sodium azide $(2 \mathrm{~g} / \mathrm{l})$ and to the dry samples $20 \mathrm{ml}$ sodium azide $(2 \mathrm{~g} / \mathrm{l})$. The centrifuge tubes were capped, shaken mechanically for $15 \mathrm{~min}$ and centrifuged $(4000 \mathrm{~g}, 5 \mathrm{~min})$. Quantification of LA in the supernatant fraction was done in a coupled enzymic reaction with $\mathrm{NAD}^{+}$after decolorizing the supernatant fraction by transferring it to a test-tube containing $1 \mathrm{~g}$ polyvinylpolypyrrolidone (Sigma Chemicals Company, St. Louis, MO, USA), precipitating coloured substances for $15 \mathrm{~min}$ and finally centrifuging $(4000 \mathrm{~g}, 5 \mathrm{~min})$. The reaction between L-LA, D-LA and $\mathrm{NAD}^{+}$is catalysed by the enzymes L-lactate dehydrogenase $(E C$ 1.1.1.27; Boehringer Mannheim $\mathrm{GmbH})$ and $\mathrm{D}(-)$-lactate dehydrogenase (EC 1.1.1.28; Boehringer Mannheim $\mathrm{GmbH}$ ). The amount of NADH formed during the oxidation of $\mathrm{NAD}^{+}$was stoichiometrically related to the amount of LA in the sample.

\section{Calculations and statistical analysis}

Each sample of effluent from the $2 \mathrm{~d}$ ingestion of inulin product was analysed for LMW sugars and inulin. Ash, starch, N, NSP, LA and SCFA analyses were done on samples pooled over the period where inulin was detected in ileal effluents (mostly 10.00-20.00 hours; the range for the lower boundary was 10.00-12.00 hours and for the higher boundary $18.00-22.00$ hours) and from periods where there was none or only trace levels of inulin in ileal effluent (08.00-10.00 hours and 20.00-08.00 hours). The last pooled samples represent periods with less frequent emptying and sampling of the ileal bags. The samples from the control day were pooled according to an average of those of the $2 \mathrm{~d}$ with inulin ingestion and the samples analysed for ash, N, starch, NSP, LMW sugars, inulin, LA and SCFA.

The mean transit time (MTT) of inulin was calculated as:

$$
\operatorname{MTT}(\mathrm{h})=\frac{\sum_{0}^{N}(\text { amount of inulin in sample }) \times t}{\text { Total inulin recovered }},
$$

where $t$ is the time interval between the test meal and recovery of inulin in effluent from sample 0 to $N$.

The results from the study were analysed as a randomized block experiment as described by Snedecor \& Cochran (1973):

$$
X_{i j}=\mu+\alpha_{i}+\beta_{j}+\epsilon_{i j},
$$

where $X_{i j}$ is the dependent variable (e.g. recovery), $\mu$ is the overall mean, $\alpha_{i}$ is the effect of levels of ingestion of inulin, $\beta_{j}$ is the block effect (individuals) and $\epsilon_{i j}$ is a normally distributed random variable. Significant differences between treatment means were identified by Scheffe's S test (Snedecor \& Cochran, 1973). All statistical calculations were done using a SuperAnova package (Abacus Concepts, Berkeley, CA, USA). 


\section{RESULTS}

The inulin product had a total carbohydrate content of $919.0 \mathrm{~g} / \mathrm{kg}$ with a distribution of $(\mathrm{g} / \mathrm{kg})$ : glucose 8.4 , fructose 18.7 , sucrose 184.3 and inulin 707.6 (Table 1 ). The fructose:glucose ratio of inulin was $4 \cdot 1$. Recoveries (\%) of sucrose and inulin in spiked samples (40 mg inulin product) were: sucrose 102 (SE 3.4), and inulin 100 (SE 2.0). On the basis of this analysis the intake of inulin (DP $>2$ ) was estimated to be $7 \cdot 1 \mathrm{~g}$ at an intake of $10 \mathrm{~g}$ inulin product and $21.2 \mathrm{~g}$ inulin at an intake of $30 \mathrm{~g}$ inulin product. The additional intakes of LMW sugars at the two levels of inulin product ingestion were $2 \cdot 1 \mathrm{~g}(10 \mathrm{~g}$ inulin product) and $6.3 \mathrm{~g}$ (30 $\mathrm{g}$ inulin product).

The average composition of the $24 \mathrm{~h}$ ileal effluent from the control day and after ingestion of $10 \mathrm{~g}$ and $30 \mathrm{~g}$ of inulin product is shown in Table 2. Total effluent increased from 413 (SE 85) $\mathrm{g}$ on the control day to 493 (SE 72) $\mathrm{g}$ and 633 (SE 93) $\mathrm{g}$ at the intakes of $10 \mathrm{~g}$ and $30 \mathrm{~g}$ inulin product respectively; the dry solid increased from 41.7 (SE 5.8 ) $\mathrm{g}$ to $56 \cdot 1$ (SE 4.9) $\mathrm{g}$ and 69.4 (SE 6.7) $\mathrm{g}$ with the same treatments. The increase in dry solid was primarily caused by a higher excretion of carbohydrate in effluent whereas ash and $N$ remained almost constant. The total amount of carbohydrate in ileal effluent was $10.2 \mathrm{~g}$ representing $331 \mathrm{~g} / \mathrm{kg}$ dry solid on the control day, increasing to $18 \cdot 1 \mathrm{~g}(331 \mathrm{~g} / \mathrm{kg})$ and $31.0 \mathrm{~g}(464 \mathrm{~g} / \mathrm{kg})$ at intakes of $10 \mathrm{~g}$ and $30 \mathrm{~g}$ inulin product respectively.

The increase in the carbohydrate content of dry solid in response to inulin ingestion was primarily caused by a higher excretion of inulin in effluent (Table 3). The basal diet provided an almost negligible amount of inulin $(0.2 \mathrm{~g})$ whereas it increased to 6.1 (SE 0.3$) \mathrm{g}$ and 18.4 (SE 0.6) $\mathrm{g}$ at the low and high intakes of inulin product respectively. LMW sugars also increased $(P<0.001)$ in response to inulin ingestion from a level of 0.7 (SE 0.1$) \mathrm{g}$ on the control day to $1 \cdot 1(\mathrm{SE} 0 \cdot 1) \mathrm{g}$ and $1 \cdot 6$ (SE $0 \cdot 1) \mathrm{g}$ at the low and high levels of inulin ingestion. In contrast there was no significant effect of the increased inulin ingestion on any of the polysaccharide fractions. The excretion of starch in ileal effluent was $1.0-1 \cdot 2 \mathrm{~g}$ $(P<0.66)$ and the excretion of NSP $8.2-9.9 \mathrm{~g}(P<0.41)$.

The passage of inulin through the gut was monitored by measuring the output of inulin in each $2 \mathrm{~h}$ collection after intakes of $10 \mathrm{~g}$ and $30 \mathrm{~g}$ inulin product respectively. As shown in Fig. 1, the average output of inulin in ileal effluent of the seven subjects after inulin ingestion increased rapidly and peaked $3 \mathrm{~h}$ after dosing at both dosing levels. At peak output levels ( $3 \mathrm{~h}$ post dosing) inulin represented approximately $230 \mathrm{~g} / \mathrm{kg}$ ileal dry solid with an intake of $10 \mathrm{~g}$ inulin product and approximately $550 \mathrm{~g} / \mathrm{kg}$ dry solid at an intake of $30 \mathrm{~g}$ inulin product. After $11 \mathrm{~h}$ the effluent was almost free of inulin.

The two levels of inulin ingestion did not affect the recovery of inulin in ileal effluent which was estimated to be 86.4 (SE 4.4 ) $\%$ at the low level of inulin ingestion and 87.0 (SE 3.3) \% $(P<0.85)$ at the high level of ingestion (Table 4). The fructose: glucose ratio of the recovered inulin in ileal effluent was 4.7 (SE 0.1) at an intake of $10 \mathrm{~g}$ inulin product and 4.5 (SE 0.1$)$ at an intake of $30 \mathrm{~g}$ inulin product $(P<0.24)$. Concurrently the recovery of the inulin glucose residue was $77 \cdot 3-80 \cdot 2 \%$, which was significantly lower $(P<0.001)$ than that of the inulin fructose residue which was about $88.5 \%$. MTT was significantly lower at the high dosing level and decreased from $4.9 \mathrm{~h}$ at the intake of $10 \mathrm{~g}$ inulin product to $3.4 \mathrm{~h}$ $(P<0.005)$ at the intake of $30 \mathrm{~g}$ inulin product. The correlation between the MTT estimated at $10 \mathrm{~g}$ and $30 \mathrm{~g}$ inulin ingested was high $(r 0.79, P<0.001)$. The recovery of inulin in ileal effluent, however, was not related to the MTT as the correlation between MTT and the recovery of inulin was only $-0.27(P<0.37)$ (Fig. 2).

To study the recovery of organic acids in freeze-dried ileal samples, wet and freeze-dried materials from the control day were analysed for LA and SCFA. Freeze-drying did not result in any significant loss of either LA or SCFA as the concentration of LA in the periods 
Table 2. Composition of the ileal effluent from ileostomy subjects consuming a control diet, or the same diet supplemented with 10 or $30 \mathrm{~g}$ inulin product*

(Mean values with their standard errors for seven ileostomy subjects)

\begin{tabular}{|c|c|c|c|c|c|c|c|}
\hline & & & \multicolumn{4}{|c|}{ Inulin product ingested $(\mathrm{g})$} & \multirow{3}{*}{$\begin{array}{c}P \text { value for } \\
\text { dietary } \\
\text { treatment }\end{array}$} \\
\hline & \multicolumn{2}{|c|}{ Control day } & \multicolumn{2}{|c|}{10} & \multicolumn{2}{|c|}{30} & \\
\hline & Mean & SE & Mean & SE & Mean & SE & \\
\hline Total effluent $(g / d)$ & 413 & 85 & 493 & 72 & 633 & 93 & 0.13 \\
\hline Total solids $(\mathrm{g} / \mathrm{d})$ & $41 \cdot 7^{\mathrm{b}}$ & $5 \cdot 8$ & $56 \cdot 1^{a, b}$ & 4.9 & $69 \cdot 4^{\mathrm{a}}$ & $6 \cdot 7$ & 0.010 \\
\hline $\operatorname{Ash}(g / d)$ & $6 \cdot 9$ & $1 \cdot 1$ & $6 \cdot 3$ & 0.7 & $7 \cdot 3$ & $1 \cdot 1$ & 0.74 \\
\hline Organic matter $(g / d)$ & $34 \cdot 8^{b}$ & $4 \cdot 8$ & $49 \cdot 3^{\mathrm{a}, \mathrm{b}}$ & $4 \cdot 3$ & $61 \cdot 2^{\mathrm{a}}$ & 5.6 & 0.004 \\
\hline Total carbohydrates $(\mathrm{g} / \mathrm{d})$ & $10 \cdot 2^{\circ}$ & $1 \cdot 1$ & $18 \cdot 1^{b}$ & 0.9 & $31 \cdot 0^{\mathrm{a}}$ & $1 \cdot 4$ & 0.001 \\
\hline Total carbohydrates (g/kg solids) & $250^{c}$ & 16 & $331^{\mathrm{b}}$ & 17 & $464^{\mathrm{a}}$ & 31 & 0.001 \\
\hline Nitrogen $(g / d)$ & $2 \cdot 1$ & $0 \cdot 3$ & $2 \cdot 5$ & 0.3 & $2 \cdot 1$ & 0.3 & 0.51 \\
\hline $\mathrm{N} \times 6.25(\mathrm{~g} / \mathrm{d})$ & $12 \cdot 9$ & $2 \cdot 1$ & $15 \cdot 5$ & 1.9 & $13 \cdot 3$ & $1 \cdot 6$ & 0.51 \\
\hline Nitrogen $\times 6.25(\mathrm{~g} / \mathrm{kg}$ solids $)$ & $308^{a}$ & 11 & $272^{\mathrm{b}}$ & 11 & $190^{\circ}$ & 9 & 0.001 \\
\hline
\end{tabular}

${ }^{\mathrm{a}, \mathrm{b}, \mathrm{e}}$ Mean values within a row with different superscript letters were significantly different $(P<0.05)$.

* For details of inulin product and procedures, see Table 1 and pp. 102-105.

Table 3. Carbohydrate composition $(\mathrm{g} / \mathrm{d})$ of the ileal effluent from ileostomy subjects consuming a control diet, or the same diet supplemented with 10 or $30 \mathrm{~g}$ inulin product* (Mean values with their standard errors for seven ileostomy subjects)

\begin{tabular}{|c|c|c|c|c|c|c|c|}
\hline & & & \multicolumn{4}{|c|}{ Inulin product ingested $(\mathrm{g})$} & \multirow{3}{*}{$\begin{array}{l}P \text { value for } \\
\text { dietary } \\
\text { treatment }\end{array}$} \\
\hline & \multicolumn{2}{|c|}{ Control day } & \multicolumn{2}{|c|}{10} & \multicolumn{2}{|c|}{30} & \\
\hline & Mean & SE & Mean & $\mathrm{SE}$ & Mean & $\mathrm{SE}$ & \\
\hline LMW sugars & $0.7^{\mathrm{c}}$ & $0 \cdot 1$ & $1 \cdot 1^{b}$ & $0 \cdot 1$ & $1 \cdot 6^{\mathrm{a}}$ & $0 \cdot 1$ & 0.001 \\
\hline Inulin & $0 \cdot 2^{\mathrm{c}}$ & $0 \cdot 1$ & $6 \cdot 1^{b}$ & $0 \cdot 3$ & $18 \cdot 4^{\mathrm{a}}$ & 0.6 & 0.001 \\
\hline Starch & 1.0 & $0 \cdot 1$ & $1 \cdot 2$ & 0.2 & $1 \cdot 2$ & $0 \cdot 2$ & 0.66 \\
\hline Total NSP & 8.2 & 0.9 & 9.8 & 0.8 & 9.9 & $1 \cdot 1$ & 0.41 \\
\hline Rhamnose & $0 \cdot 1$ & 0.01 & $0 \cdot 1$ & 0.02 & $0 \cdot 1$ & 0.02 & 0.80 \\
\hline Fucose & 0.5 & 0.05 & 0.5 & 0.05 & 0.5 & 0.05 & 0.49 \\
\hline Arabinose & $1 \cdot 4$ & 0.2 & 1.7 & $0 \cdot 2$ & 16 & 0.2 & 0.52 \\
\hline Xylose & 1.9 & $0 \cdot 3$ & $2 \cdot 4$ & 0.2 & $2 \cdot 4$ & $0-3$ & 0.36 \\
\hline Mannose & 0.6 & 0.1 & 0.8 & 0.1 & 0.9 & $0 \cdot 1$ & $0 \cdot 16$ \\
\hline Galactose & $1 \cdot 3$ & 0.2 & $1 \cdot 4$ & 0.2 & $1 \cdot 5$ & $0 \cdot 2$ & 0.57 \\
\hline Glucose & $2 \cdot 3$ & 0.2 & $2 \cdot 6$ & 0.2 & $2 \cdot 7$ & $0 \cdot 3$ & 0.41 \\
\hline Uronic acids & 0.2 & 0.03 & $0 \cdot 2$ & 0.02 & $0 \cdot 2$ & 0.03 & 0.99 \\
\hline
\end{tabular}

LMW sugars, low-molecular-weight sugars (glucose, fructose and sucrose); NSP, non-starch polysaccharides.

$a, b, c$ Mean values within a row with different superscript letters were significantly different $(P<0.05)$.

* For details of inulin product and procedures, see Table 1 and pp. 102-105.

with frequent collections was 7.3 (SE 0.6) mmol/1 in wet samples and $5.9(\mathrm{SE} \mathrm{0.9)} \mathrm{mmol} / 1$ in freeze-dried samples $(P<0.42)$ and the concentration of SCFA was 51.7 (SE 13.2) mmol/1 in wet samples and 55.4 (SE 12.0) mmol/1 in freeze-dried samples $(P<0.71)$ (Table 5). In periods with less frequent collections the concentration of LA estimated in wet samples was 10.4 (SE 1.1) mmol/l and in freeze-dried samples 10.1 (SE 2.3$) \mathrm{mmol} / 1(P<0.54)$, and that of SCFA in wet samples was 83.9 (SE 16.3) mmol/1 compared with 83.3 (SE 11.3) mmol/1 in 


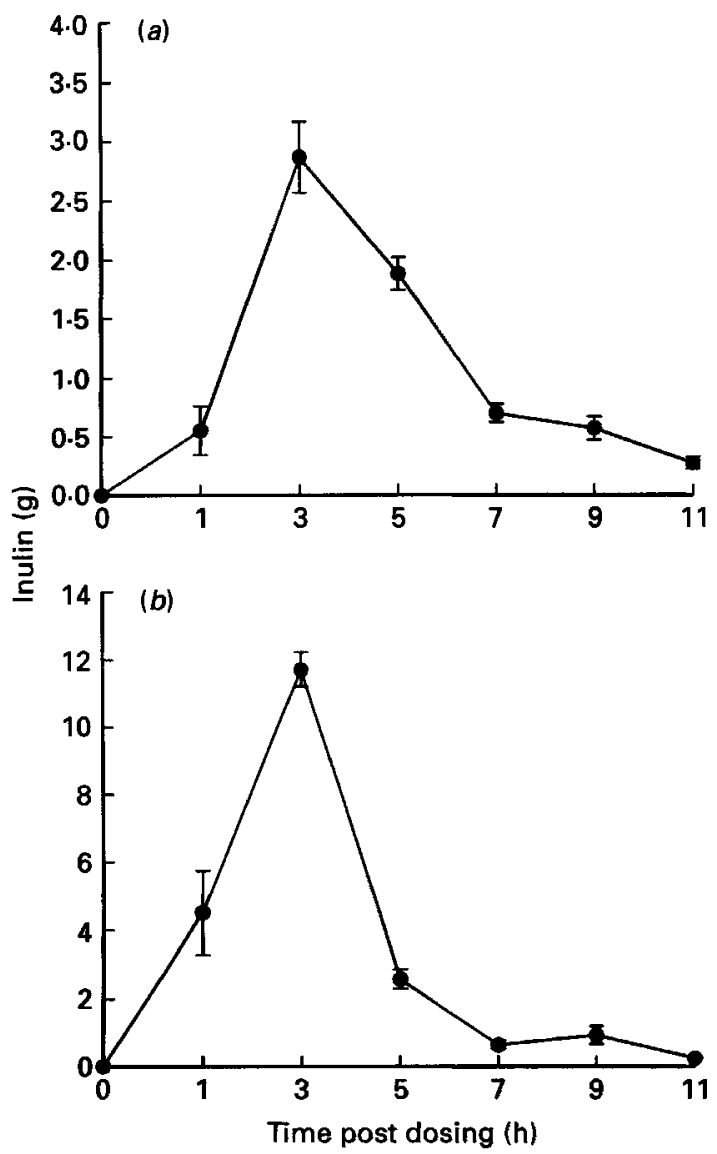

Fig. 1. Recovery of inulin (g) in ileal effluent following ingestion of $(a) 10 \mathrm{~g}$ and $(b) 30 \mathrm{~g}$ inulin product on successive days. The values are means of seven ileostomy subjects with their standard errors represented by vertical bars.

Table 4. Excretion of inulin in ileal effluent, and mean transit time (MTT) of inulin in ileostomy subjects consuming a control diet, or the same diet supplemented with 10 or $30 \mathrm{~g}$ inulin product*

(Mean values with their standard errors for seven ileostomy subjects)

\begin{tabular}{|c|c|c|c|c|c|c|c|}
\hline & & & \multicolumn{4}{|c|}{ Inulin product ingested (g) } & \multirow{3}{*}{$\begin{array}{c}P \text { value for } \\
\text { dietary } \\
\text { treatment }\end{array}$} \\
\hline & \multicolumn{2}{|c|}{ Control day } & \multicolumn{2}{|c|}{10} & \multicolumn{2}{|c|}{30} & \\
\hline & Mean & SE & Mean & SE & Mean & SE & \\
\hline Inulin $(\mathrm{g} / \mathrm{d})$ & $0 \cdot 2^{\mathrm{c}}$ & $0 \cdot 1$ & $6 \cdot 1^{\mathrm{b}}$ & 0.3 & $18 \cdot 4^{a}$ & 0.6 & 0.001 \\
\hline Fructose: Glucose ratio of inulin & - & & $4 \cdot 7$ & 0.1 & 4.5 & 0.1 & 0.24 \\
\hline Inulin recovery $(\%)$ & - & & $86 \cdot 4$ & $4 \cdot 4$ & 87.0 & 3.1 & 0.85 \\
\hline Inulin-glucose recovery $(\%)$ & - & & $77 \cdot 3$ & 4.7 & $80 \cdot 2$ & 2.5 & 0.52 \\
\hline Inulin-fructose recovery $(\%)$ & - & & $88 \cdot 5$ & $4 \cdot 3$ & $88 \cdot 4$ & $3 \cdot 3$ & 0.97 \\
\hline MTT inulin (h) & - & & $4 \cdot 9^{\mathrm{a}}$ & 0.6 & $3 \cdot 4^{\mathrm{b}}$ & 0.3 & 0.005 \\
\hline
\end{tabular}

$\mathrm{a}, \mathrm{b}, \mathrm{c}$ Mean values within a row with different superscript letters were significantly different $(P<0.05)$.

* For details of inulin product and procedures, see Table 1 and pp. 102-105. 


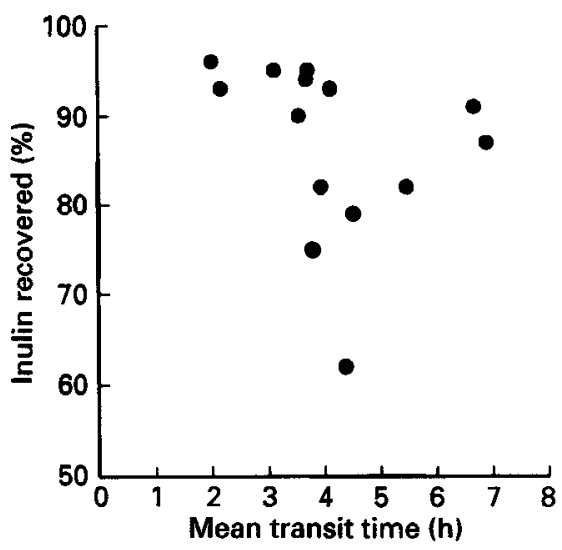

Fig. 2. Correlation between the recovery of inulin (as a percentage of inulin intake) in ileal effluent, and the mean transit time of inulin through the small intestine. $r-0.27, P<0.37$.

Table 5. Lactic acids $(L A)$ and short-chain fatty acids $(S C F A)$ in pooled wet and freezedried ileal effluent from ileostomy subjects fed on a low-dietary-fibre basal diet*

(Mean values with their standard errors for seven ileostomy subjects)

\begin{tabular}{|c|c|c|c|c|c|c|c|c|}
\hline \multirow[b]{2}{*}{ Period $\dagger$} & \multicolumn{4}{|c|}{ LA (mmol/l) } & \multicolumn{4}{|c|}{ SCFA $(\mathrm{mmol} / \mathrm{l})$} \\
\hline & Wet & Freeze-dried & SE & $P$ value & Wet & Freeze-dried & SE & $P$ value \\
\hline 1 & $7 \cdot 3$ & 5.9 & 0.7 & 0.42 & $51 \cdot 7$ & $55 \cdot 4$ & $13 \cdot 4$ & 0.71 \\
\hline 2 & $10 \cdot 4$ & $10 \cdot 1$ & $1 \cdot 2$ & 0.54 & 83.9 & $83 \cdot 3$ & 15.0 & 0.91 \\
\hline
\end{tabular}

* For details of diet and procedures, see pp. 102-105.

$\dagger$ Period 1, pooled effluent from 10.00-20.00 hours; Period 2, pooled effluent from 08.00-10.00 hours and $20.00-08.00$ hours.

freeze-dried samples $(P<0.91)$. The overall correlation between LA and SCFA estimated on wet or freeze-dried materials respectively, was $0.95(P<0.001)$ for LA and 0.99 $(P<0.001)$ for SCFA.

The concentration of LA in the ileal effluents collected frequently was 5.9 (SE 0.9 ) mmol/1 on the control day. This level increased to 25.8 (SE 7.3) mmol/l at the low ingestion level of inulin and to 18.5 (SE 6.8) $\mathrm{mmol} / 1$ at the high ingestion level of inulin $(P<0.052$; Table 6). The opposite was the case with the concentration of SCFA, which decreased from 55.4 (SE 12.0) $\mathrm{mmol} / \mathrm{l}$ in the effluent from the control day to a level of 31.9 (SE 8.1$) \mathrm{mmol} / \mathrm{l}$ at an ingestion of $10 \mathrm{~g}$ inulin product and 18.3 (SE 3.6) $\mathrm{mmol} / \mathrm{l}$ at an ingestion of $30 \mathrm{~g}$ inulin product $(P<0.023)$. The concentration of SCFA in ileal effluent was in general higher during periods with less frequent collections with values in the range $52.7-83.3 \mathrm{mmol} / 1$. The same was the case with LA on the control day, while the opposite was the case on days with inulin ingestion. The excretion of LA in ileal effluent over $24 \mathrm{~h}$ increased from 2.7 (SE 0.4) $\mathrm{mmol} / \mathrm{d}$ on the control day to 7.0 (SE 2.0) and 8.8 (SE 1.9) $\mathrm{mmol} / \mathrm{d}$ with ingestion levels of $10 \mathrm{~g}$ and $30 \mathrm{~g}$ inulin product respectively. The reverse was seen with SCFA, which decreased from 23.6 (SE 3.8) mmol/d on the control day to 15.5 (SE 2.3) and 15.8 (SE 2.8) $\mathrm{mmol} / \mathrm{d}$ at $10 \mathrm{~g}$ and $30 \mathrm{~g}$ inulin product ingested respectively.

Acetic acid was the predominant SCFA in ileal effluent accounting for 0.88-0.90 of the acids, while propionic acid (0.02-0.05) and butyric acid (0.05-0.06) were minor components. 
Table 6. Organic acid content of ileal effuent from ileostomy subjects consuming a control diet, or the same diet supplemented with 10 or $30 \mathrm{~g}$ inulin product ${ }^{*}$

(Mean values with their standard errors for seven ileostomy subjects)

\begin{tabular}{|c|c|c|c|c|c|c|c|}
\hline & & & \multicolumn{4}{|c|}{ Inulin product ingested $(\mathrm{g})$} & \multirow{3}{*}{$\begin{array}{c}P \text { value for } \\
\text { dietary } \\
\text { treatment }\end{array}$} \\
\hline & \multicolumn{2}{|c|}{ Control day } & \multicolumn{2}{|c|}{10} & \multicolumn{2}{|c|}{30} & \\
\hline & Mean & $\mathrm{SE}$ & Mean & SE & Mean & SE & \\
\hline LA (mmol/1)/Period 1 & 5.9 & 0.9 & $25 \cdot 8$ & $7 \cdot 3$ & $18 \cdot 5$ & 68 & 0.052 \\
\hline LA (mmol/1)/Period 2 & $10 \cdot 1$ & $2 \cdot 3$ & $9 \cdot 4$ & $4 \cdot 0$ & $15 \cdot 1$ & 4.9 & 0.43 \\
\hline SCFA (mmol/1)/Period 1 & $55 \cdot 4^{\mathrm{a}}$ & $12 \cdot 0$ & $31 \cdot 9^{\mathrm{a}, \mathrm{b}}$ & $8 \cdot 1$ & $18 \cdot 3^{\mathrm{b}}$ & 3.6 & 0.023 \\
\hline SCFA (mmol/l)/Period 2 & $83 \cdot 3$ & $11 \cdot 4$ & $52 \cdot 7$ & $10 \cdot 0$ & $59 \cdot 0$ & $16 \cdot 6$ & $0 \cdot 26$ \\
\hline \multicolumn{8}{|l|}{ SCFA (proportion of total) $\dagger$} \\
\hline Acetic acid & 0.90 & 0.02 & 0.89 & 0.02 & 0.88 & 0.02 & $0 \cdot 59$ \\
\hline Propionic acid & 0.02 & 0.01 & 0.05 & 0.02 & 0.05 & 0.02 & 0.08 \\
\hline Butyric acid & 0.06 & 0.002 & 0.05 & 0.02 & 0.06 & 0.02 & 0.65 \\
\hline $\mathrm{LA}(\mathrm{mmol} / \mathrm{d})$ & $2 \cdot 7^{\mathrm{b}}$ & 0.4 & $7 \cdot 0^{\mathrm{a}, \mathrm{b}}$ & $2 \cdot 0$ & $8 \cdot 8^{a}$ & 1.9 & 0.021 \\
\hline SCFA (mmol/d) & $23 \cdot 6$ & 3.8 & $15 \cdot 5$ & $2 \cdot 3$ & $15 \cdot 8$ & $2 \cdot 8$ & 0.162 \\
\hline
\end{tabular}

Period 1, pooled effluent from 10.00-20.00 hours; Period 2, pooled effluent from 08.00-10.00 hours and 20.00-08.00 hours. LA, lactic acid; SCFA short-chain fatty acids.

$\mathbf{a}, \mathbf{b}, \mathbf{e}$ Mean values within a row with different superscript letters were significantly different $(P<0.05)$.

* For details of diet and procedures, see pp. 102-105.

$\uparrow$ Pooled effluents from Periods 1 and 2.

\section{DISCUSSION}

The present study, performed with ileostomists, demonstrates that inulin is practically indigestible in the small intestine of man. The recovery of inulin in ileal effluent was approximately $87 \%$ at both the low $(10 \mathrm{~g}$ inulin product) and the high ( $30 \mathrm{~g}$ inulin product) intake levels, thus confirming in vitro studies using human saliva, rat pancreas homogenates, and rat and human small-intestinal mucosa which demonstrated that inulin is hydrolysed only marginally by mammalian intestinal enzymes (Oku et al. 1984; Nilsson et al. 1988). The results of the present study are also in good agreement with human studies using the breath $\mathrm{H}_{2}$ test, which have concluded that inulin is virtually completely unabsorbed in the upper part of the small intestine (Stone-Dorshow \& Levitt, 1987; Rumessen et al. 1990).

The small, though significant, loss of inulin during passage through the small intestine may be due to hydrolysis by either acid or enzymes or to microbial degradation by the microflora permanently colonizing the distal small intestine. The significant change in the fructose: glucose ratio of inulin from ingestion (fructose: glucose $4 \cdot 1$ ) to recovery in the ileal effluent $(4 \cdot 5-4 \cdot 7)$ strongly indicates that low-molecular-weight components of inulin are more sensitive to hydrolysis than the high-DP fragments. In experiments with Neosugar ${ }^{\circledR}$ (a fructo-oligosaccharide with two to four fructosyl residues linked to a terminal glucose; Meiji Seika Kaisha Ltd., Kanto, Japan; Oku et al. 1984) it has been found that the hydrolysis by rat intestinal mucosa occurs at a rate $<0.5 \%$ of that of sucrose. The likely cause is that the enzyme affinity for the low-molecular-weight fructo-oligosaccharides, when compared with that for sucrose, is affected by the higher molecular size. It is therefore more likely that the hydrolysis of the low-DP inulin is due to gastric juice. In an in vitro study with isolated fructan fractions from wheat, Nilsson et al. (1988) found a hydrolysis of $15-16 \%$ per $h$ for fructans with DP of 3 and 4 at a pH of 1 declining to about $5 \%$ per $h$ at a $\mathrm{pH}$ of 1.5 . These hydrolyses of cereal fructans were similar to that of sucrose but higher than that of a cereal fructan with a DP of 9 . However, it should be mentioned that 
the $\mathrm{pH}$ used in these in vitro experiments is presumably lower than in vivo when the $\mathrm{pH}$ is buffered by the bolus.

Potentially inulin could also be fermented by the microbial population colonizing the distal part of the small intestine. A major difference between the normal ileum and that of the ileostomists is indeed its microbial population, which is greater in the ileostomists $\left(10^{7}-10^{8}\right.$ bacteria $\left./ \mathrm{g}\right)$ compared with the normal ileum $\left(10^{5}-10^{8}\right.$ bacteria $/ \mathrm{g}$; Finegold et al. 1970; Drasar \& Hill, 1974). The outcome of this colonization is the microbial breakdown of carbohydrates and the formation of LA and SCFA. In the present study we found a concentration of LA of approximately $6 \mathrm{mmol} / \mathrm{l}$ and of SCFA of approximately $55 \mathrm{mmol} / 1$ on the control day with a tendency towards a lower concentration of the acids in periods with frequent collections (10.00-20.00 hours) compared with less frequent collections (mostly night). The levels of SCFA found in the present study are far higher than previously reported by Englyst \& Cummings (1986) who failed to reveal SCFA at $>3-9 \mathrm{mmol} / 1$ concentrations in any ileostomy subjects, but lower than in the caecum where fermentation is active and the concentration of SCFA is well in excess of $100 \mathrm{mmol} / 1$ (Cummings $e t$ al. 1987). In spite of the higher level of organic acids in ileal effluents compared with previous findings by Englyst \& Cummings (1986) there was no indication of either a higher concentration of organic acids or an increased excretion in the presence of inulin. This is presumably due to the fact that the capacity of the microflora for metabolizing carbohydrates into organic acids is met even with the level of carbohydrate present on the control day. However, the results seem to indicate that the type of substrate utilized by the flora may have been altered from the control day to periods with inulin ingestion resulting in a change in the nature of the fermentation products formed. The losses of inulin from ingestion to recovery in the ileum amounted to 1.1 and $3.4 \mathrm{~g} / \mathrm{d}$ at the low and high ingestion levels of inulin respectively, which can be compared with an increased excretion of $2 \cdot 2$ and $2.8 \mathrm{~g} / \mathrm{d}$ of LMW sugars, starch and NSP, at the two ingestion levels of inulin respectively. Thus, approximately the same amount of carbohydrate was fermented $(2-3 \mathrm{~g} / \mathrm{d}$ as calculated from the excretion of LA and SCFA) but the nature of the fermentation products changed (more LA at the expense of SCFA), perhaps because of changes in substrate: i.e. in the presence of inulin, bacteria utilize it in preference to starch and NSP.

Neither the concentration of organic acids nor the total excretion of organic acids in ileal effluent is therefore regulated by dietary composition but is a result of the permanent flora colonizing this part of the gastrointestinal tract. The molar composition of SCFA in ileal effluent is quite constant and typical for materials collected from the small intestine of man and single-stomached animals like the pig (Cummings et al. 1987; Bach Knudsen et al. 1993). For comparison it can be mentioned that while acetic acid typically accounts for $80-90 \%$ of the pool of SCFA in the distal small intestine of man and pigs, acetic acid decreases to 50-60\% of SCFA in the caecum (Cummings et al. 1987; Bach Knudsen et al. 1993).

The transit of inulin through the small intestine was rapid, with a MTT of 4.9 (SE 0.6) $\mathrm{h}$ at an ingestion of $10 \mathrm{~g}$ inulin product and 3.4 (SE 0.3$) \mathrm{h}$ at an ingestion of $30 \mathrm{~g}$ inulin product. In contrast to what was found for resistant starch type 3 (retrograded amylose), where the correlation between MTT and the recovery was found to be highly significant $(r-0 \cdot 6)$, the correlation between MTT and the recovery of inulin was only $-0 \cdot 27$. The transit of inulin through the small intestine is faster than that of NSP in mixed diets where MTT of potato, banana and cereal were estimated to be 6-8 h (Englyst \& Cummings, 1985, $1986,1987)$. The MTT of inulin in the present study, however, was longer than that found using the breath $\mathrm{H}_{2}$ test where the orocaecal transit time was found to be about $3 \mathrm{~h}$ for $10 \mathrm{~g}$ inulin product compared with about $7 \mathrm{~h}$ for $50 \mathrm{~g}$ wheat starch when the two carbohydrate sources were provided as the sole source of carbohydrate (Rumessen et al. 1990). 
Although the osmotic load ( 68 and $204 \mathrm{mosmol} / 1$ ) was within the safe osmotic range of the small intestine, ingestion of inulin resulted in a minor malabsorption of LMW sugars. In response to the increased intake of inulin there was an associated increase in LMW sugars in ileal effluent which increased from $0.7 \mathrm{~g} / \mathrm{d}$ on the control day to $1.1 \mathrm{~g} / \mathrm{d}$ with an intake of $10 \mathrm{~g}$ inulin product, and further to $1.6 \mathrm{~g} / \mathrm{d}$ with an intake of $30 \mathrm{~g}$ inulin product. The increase in LMW sugars of ileal effluent is minor relative to the other carbohydrates but the difference was highly significant and in striking contrast to that found for the polysaccharides. Neither the output of starch nor total NSP and its residues were influenced by the ingestion of inulin. Furthermore, in spite of the fact that the inulin was not given together with the breakfast meal the result is consistent with an earlier finding showing that inulin, in contrast to some dietary fibres, does not influence wheat starch absorption when inulin and wheat starch are provided together (Rumessen et al. 1990).

In terms of indigestibility inulin shares many features with dietary fibre (Roberfroid, 1993). The recovery is within the same order as found for soluble fibres like pectin (Sandberg et al. 1983), while it is slightly lower than that reported for cereal foods by Englyst \& Cummings (1985) and potato by Schweizer et al. (1990). On the basis of its indigestibility it would therefore be natural to consider inulin or oligofructose and other non-digestible oligosaccharides in the same way as dietary fibre components. These substances all provide energy to the microbial population that inhabits the human caecum and colon. In addition, inulin may have some specific beneficial properties for the microbial metabolism in the large intestine (Hidaka et al. 1986; Roberfroid et al. 1993). Studies have shown that inulin serves as a selective growth substrate for bifidobacteria.

In conclusion, the present study shows that inulin, isolated from Jerusalem artichoke, is virtually indigestible in the small intestine of man. In terms of indigestibility the inulin, like other oligofructoses, has features similar to those of dietary fibre.

The authors are indebted to B. O. Eggum, J. Van Loo, Tiense Suikerraffinaderij, Belgium and M. Roberfroid, Université Catholique de Louvain, Belgium for comments on the manuscript. They also would like to thank Kirsten Ditlev Østergaard and Hanne Lund Jensen for excellent technical assistance.

\section{REFERENCES}

Archbold, H. K. (1940). Fructosans in the monocotyledons. A review. New Phytologist 39, 185-219.

Association of Official Analytical Chemists (1990). Official Methods of Analysis. Arlington, Virginia: Association of Official Analytical Chemists.

Bach Knudsen, K. E., Åman, P. \& Eggum, B. O. (1987). Nutritive value of Danish-grown barley varieties. I. Carbohydrates and other major constituents. Journal of Cereal Science 6, 173-186.

Bach Knudsen, K. E., Jensen, B. B. \& Hansen, I. (1993). Digestion of polysaccharides and other major components in the small and large intestine of pigs fed on diets consisting of oat fractions rich in $\beta$-D-glucan. British Journal of Nutrition 70, 537-556.

Cummings, J. H. \& Englyst, H. N. (1991). Measurement of starch fermentation in the human large intestine. Canadian Journal of Physiology and Pharmacology 69, 121-129.

Cummings, J. H., Pomare, E. W., Branch, W. J., Naylor, C. P. E. \& Macfarlane, G. T. (1987). Short chain fatty acids in human large intestine, portal, hepatic and venous blood. Gut 28, 1221-1227.

De Bruyn, A. \& Van Loo, J. (1991). The identification by 1H- and 13C NMR spectroscopy of sucrose, 1-kestose, and neokestose in mixtures present in plant extracts. Carbohydrate Research 212, 131-136.

De Leenheer, L. \& Hoebregs, H. (1994). Progress in the elucidation of the composition of chicory inulin. Starch 46, 193-196.

Deis, R. C. (1994). Adding bulk without adding sucrose. Cereal Foods World 2, 93-97.

Drasar, B. S. \& Hill, M. J. (1974). The distribution of bacterial flora in the intestine. In Human Intestinal Flora, pp. 36-50 [B. S. Drasar and M. J. Hill editors]. London: Academic Press.

Englyst, H. N. \& Cummings, J. H. (1985). Digestion of polysaccharides of some cereal foods in the human small intestine. American Journal of Clinical Nutrition 42, 778-787.

Englyst, H. N. \& Cummings, J. H. (1986). Digestion of the carbohydrates of banana (Musa paradisiaca sapientum) in the human small intestine. American Journal of Clinical Nutrition 44, 42-50. 
Englyst, H. N. \& Cummings, J. H. (1987). Digestion of polysaccharides of potato in the small intestine of man. American Journal of Clinical Nutrition 45, 423-431.

Englyst, H. N., Wiggins, H. S. \& Cummings, J. H. (1982). Determination of non-starch polysaccharides in plant foods by gas-liquid chromatography of constituent sugars as alditol acetates. Analyst 107, 307-318.

Finegold, S. M., Sutter, V. L., Boyle, J. D. \& Shimada, K. (1970). The normal flora of ileostomy and transverse colostomy effluents. Journal of Infectious Diseases 122, 376-381.

Fleming, S. E. \& GrootWassink, J. W. D. (1979). Preparation of high-fructose syrup from the tubers of the Jerusalem artichoke (Helianthus tuberosus L.). CRC Critical Reviews in Food Science and Nutrition 12, 1-28.

Fussell, R. J. \& McCalley, D. V. (1987). Determination of volatile fatty acids $\left(C_{2}-C_{5}\right)$ and lactic acid in silage by gas chromatography. Analyst 112, 1213-1216.

Hidaka, H., Eida, T., Takizawa, T., Tokunaga, T. \& Tashiro, Y. (1986). Effects of fructo-oligosaccharides on intestinal flora and human health. Bifidobacteria Microflora 5, 37-50.

Hirst, E. L. (1957). Some aspects of the chemistry of the fructosans. Chemical Society Proceedings, 193-204.

Langkilde, A. M., Andersson, H., Schweizer, T. F. \& Torsdottir, I. (1990). Nutrients excreted in ileostomy effluents after consumption of mixed diets with beans or potatoes. I. Minerals, protein, fat and energy. European Journal of Clinical Nutrition 44, 559-566.

Nilsson, U., Öste, R., Jägerstad, M. \& Birkhed, D. (1988). Cereal fructans: in vitro and in vivo studies on availability in rats and humans. Journal of Nutrition 118, 1325-1330.

Oku, T., Tokunga, T. \& Hosoya, N. (1984). Nondigestibility of a new sweetener, "Neosugar", in the rat. Journal of Nutrition 114, 1574-1581.

Quemener, B., Thibault, J.-F. \& Coussement, P. (1994). Determination of inulin and oligofructose in food products, and integration in the AOAC method for measurement of total dietary fibre. LebenmittelWissenschaft und-Technologie 27, 125-132.

Roberfroid, M. (1993). Dietary fiber, inulin, and oligofructose: a review comparing their physiological effects. CRC Critical Reviews in Food Science and Nutrition 33, 103-148.

Roberfroid, M., Gibson, G. R. \& Delzenne, N. (1993). The biochemistry of oligofructose, a nondigestible fiber: an approach to calculate its caloric value. Nutrition Reviews 51, 137-146.

Rumessen, J. J., Bodé, S., Hamberg, O. \& Gudmand-Høyer, E. (1990). Fructans of Jerusalem artichokes: intestinal transport, absorption, fermentation, and influence on blood glucose, insulin, and C-peptide response in healthy subjects. American Journal of Clinical Nutrition 52, 675-681.

Sandberg, A.-S., Ahderinne, R., Andersson, H., Hallgreen, B. \& Hultén, L. (1983). The effect of citrus pectin on the absorption of nutrients in the small intestine. Human Nutrition: Clinical Nutrition 37C, 171-183.

Schweizer, T. F., Andersson, H., Langkilde, A. M., Reimann, S. \& Torsdottir, I. (1990). Nutrients excreted in ileostomy effluents after consumption of mixed diets with beans or potatoes. II. Starch, dietary fibre and sugars. European Journal of Clinical Nutrition 44, 567-575.

Scott, R. W. (1979). Colorimetric determination of hexuronic acids in plant materials. Analytical Chemistry 51, 936-941.

Snedecor, G. W. \& Cochran, W. G. (1973). Statistical Methods. Ames: Iowa State University Press

Stone-Dorshow, T. \& Levitt, M. D. (1987). Gaseous response to ingestion of poorly absorbed fructooligosaccharide sweetener. American Journal of Clinical Nutrition 46, 61-65.

Theander, O. \& Åman, P. (1979). Studies on dietary fibre. 1. Analysis and chemical characterization of watersoluble and water-insoluble dietary fibres. Swedish Journal of Agricultural Research 9, 97-106.

Theander, O. \& Westerlund, E. A. (1986). Studies on dietary fiber. 3. Improved procedures for analysis of dietary fiber. Journal of Agricultural and Food Chemistry 34, 330-336.

Van Loo, J., Coussement, P., De Leenheer, L., Hoebergs, L. \& Smits, G. (1995). On the presence of inulin and oligofructose as natural ingredients in the western diet. CRC Critical Reviews in Food Science and Nutrition (In the Press.)

Wang, X. \& Gibson, G. (1993). Effects of the in vitro fermentation of oligofructose and inulin by bacteria growing in the large intestine. Journal of Applied Bacteriology 75, 373-380.

Yamashita, K., Kawai, K. \& Itakura, M. (1984). Effects of fructo-oligosaccharides on blood glucose and serum lipids in diabetic subjects. Nutrition Research 4, 961-966. 